JIOM Nepal, Volume 41, Number 2, August 2019, page 59-61

\title{
Challenges of Sustaining Elimination Status of Leprosy in Nepal
}

\author{
'Sudip Parajuli, 'Dinesh B Pokhrel, 'Rabindra Baskota , ${ }^{3}$ Amod Poudyal, 'Upama Paudel \\ 1'Department of Dermatology and Venereology, Maharajgunj Medical Campus, Tribhuvan University Teaching Hospital, \\ Maharajgunj, Kathmandu, Nepal \\ ${ }^{2}$ Leprosy Control and Disability Management Section, Ministry of Health and Population, Government of Nepal \\ ${ }^{3}$ Central Department of Public Health, Institute of Medicine, Maharajgunj, Kathmandu, Nepal
}

\section{Corresponding author:}

Upama Paudel, MBBS, MD

Department of Dermatology and Venereology, Maharajgunj Medical Campus, Tribhuvan University Teaching Hospital, Maharajgunj, Kathmandu, Nepal

Email: upama_ups@yahoo.com

Submitted: Jun 6, 2019

Accepted : Jul 24, 2019

\begin{abstract}
Introduction

The number of leprosy patients is increasing in Nepal even after declaration of elimination in 2010. The objective of this study was to review the status of leprosy after declaration of elimination in Nepal and to identify challenges to sustain elimination.

\section{Methods}

This was retrospective study conducted by reviewing the annual data published by Department of Health Services, Ministry of Health, Government of Nepal from 2010 through 2018. In addition, one year hospital based data (2017/18) was retrieved from records of Department of Dermatology and Venereology, Tribhuvan University Teaching Hospital, Kathmandu, Nepal.

\section{Results}

The prevalence of leprosy was found to be $0.77 / 10,000$ population in 2010 and $0.99 / 10,000$ in 2018 . The numbers of multibacillary (MB) cases (remained more than $50 \%$ ) outnumbered paucibacillary (PB) cases throughout eight years.
\end{abstract}

\section{Conclusion}

The prevalence of leprosy is gradually increasing in Nepal with more number of multibacillary cases detected in post-elimination era.

Keywords: Leprosy, multibacillary, paucibacillary

\section{INTRODUCTION}

$$
1
$$

eprosy, also known as Hansen's disease is chronic infectious disease caused by Mycobacterium leprae and affects skin and peripheral nerves. The cardinal signs of leprosy includes (1) anaesthesia of skin lesions, or in the distribution of peripheral nerves, or over dorsal surface of hands and feet (2) thickened nerves especially at the site of predilection and (3) typical skin lesions. The diagnosis is made by presence of two out of three cardinal signs or by demonstration of slit skin smear, or by histology typical of leprosy. ${ }^{1}$ Based on number of skin lesions, slit skin smear positivity and nerve involvement world health organization (WHO) classifies a new case of leprosy as paucibacillary (one to five number of lesions) and multibacillary (more than five number of lesions or slit skin smear positive irrespective of number of skin lesions or pure neuritis or any number of skin lesion with neuritis). ${ }^{2}$ Multibacillary leprosy corresponds to more contagious forms of leprosy and is major source of transmission in community.

Elimination of leprosy as public health problem (defined as point prevalence of less than 1 case per 10,000 population) was achieved globally in 2000 and at national level in most countries by $2005 .^{2}$ However, in many countries where the disease is endemic the incidence of disease has not decreased significantly and there are large number of population who live with disability post cure. There were 113,118 cases at the end of 2017, with prevalence corresponding to $0.3 / 10000 .^{3}$

Elimination of Leprosy in Nepal was declared in January 2010.4 After achieving elimination the 


\section{PREVALENCE RATE /10,000}

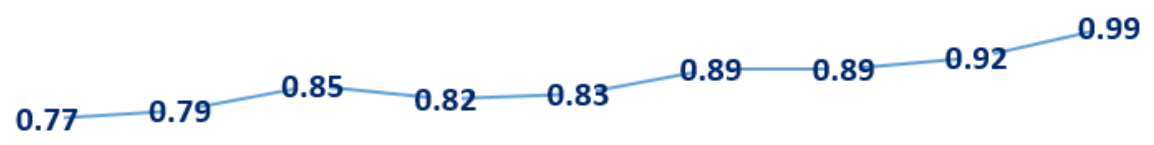

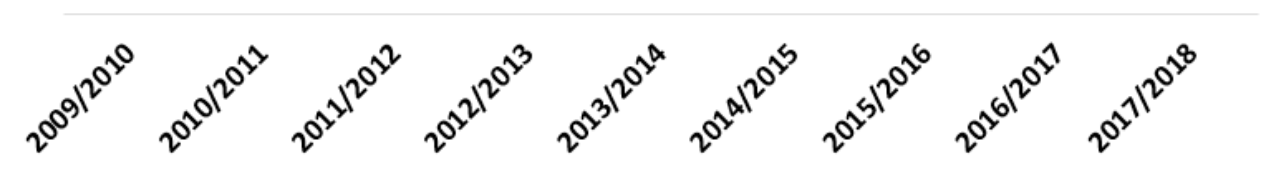

Figure 1. Trends of prevalence of leprosy (2010-2018)

national strategy was revised to "Sustain quality leprosy services and further reduce the disease burden due to leprosy in Nepal: 2011-2015" and major target for 2020 was set to reduce grade 2 disability below 1 per million population. Despite this elimination achievement and changing the strategy, the significant number of leprosy cases has been diagnosed annually. Prevalence at the time of declaration of elimination was $0.77 / 10,000$ in 2010 and the prevalence reported in $2017 / 18$ has increased to $0.99 / 10,000$ according to statistics of Department of health services (DoHS) Nepal. ${ }^{5}$ In all the reports published since 2010, it is seen that detection of multibacillary cases outnumbers paucibacillary cases and remained above $50 \% .^{4}$ This calls for review of elimination status and identify challenges to sustain elimination in our country.

\section{METHODS}

We reviewed data of annual report of Department

Table 1. Number of new cases detected in Nepal (2009-2018)

\begin{tabular}{cc}
\hline Year & No. of cases \\
\hline $2009 / 10$ & 3157 \\
$2010 / 11$ & 3142 \\
$2011 / 12$ & 3481 \\
$2012 / 13$ & 3253 \\
$2013 / 14$ & 3223 \\
$2014 / 15$ & 3053 \\
$2015 / 16$ & 3054 \\
$2016 / 17$ & 3215 \\
$2017 / 18$ & 3249 \\
\hline
\end{tabular}

of Health Services, Government of Nepal data since declaration of its elimination since 2010 through June 2019. We also reviewed one year (June 2017 through May 2018) hospital record of Department of Dermatology and Venereology, Tribhuvan University Teaching Hospital, one of the tertiary care centre of Kathmandu, Nepal. The variables studied included number of new cases, prevalence rate and types of Hansen's disease. The strategies of government of Nepal for leprosy elimination was reviewed. This study was conducted as per the declaration of Helsinki.

\section{RESULTS}

The number of new cases detected remained around 3000 every year (Table 1). The prevalence rate of Hansen disease per 10,000 population was 0.77 in 2009/2010 and reached to 0.99 in 2017/18 (Figure 1). The percentage of Multibacillary Hansens disease remained around $50 \%$ in most of these years with $54 \%$ in 2017/18.

The data of Tribhuvan University Teaching Hospital revealed that $1,68,984$ patients attended Dermatology Outpatient Department in the study period amongst which there were 47 new cases of leprosy out of which 42 patients (89.7\%) were MB cases and $5(10.3 \%)$ patients were PB cases.

\section{DISCUSSION}

The review of national data along with hospital based data in this study showed that the prevalence of leprosy is gradually increasing in Nepal over a period of eight years, though elimination was declared long time back. Furthermore, the study showed MB cases outnumbering PB cases in years which followed after declaration of elimination. Presence of more number of $\mathrm{MB}$ cases in community shows that there is 
ongoing transmission of disease and the numbers of leprosy cases are going to increase in coming years.

On reviewing the other literature from Nepal and few from India, the observations we made were almost similar to those made by them. In one of the study done in a single centre by Upama et al, ${ }^{6} 0.24 \%$ were new cases of Leprosy out of which $50 \%$ were MB cases. In a study from India by Singal $A,{ }^{7}$ it was seen that pockets of endemicity with prevalence rate of $>1 / 10000$ still exists in many parts of India though elimination was achieved in 2005.In an analysis of elimination of Leprosy in India by Sengupta, ${ }^{8}$ he pointed out the reasons behind increase in leprosy cases post elimination and concluded that the active cases detection, chemoprophylaxis in contacts, reduction in default rate, contact tracing, reduction in stigma, education of public about signs and symptoms of leprosy, and vaccines might be essential in future to make leprosy free society.

Our observations raises important question in scenario of leprosy in Nepal i,e "Are we reaching towards prevalence of pre-elimination era?". The answer to this question might be evident in following years to come. However, at this point of time we think following queries remain still unanswered and needs to be pondered on. First, was the case defining criteria inappropriate? Second, is elimination understood as eradication? Third, less attention (reduced priority) at all levels? Fourth, lack of trained human resources and drugs? And final, treatment failure or relapse (No proper Surveillance?). The challenges which we think needs to be addressed at this point of time are i) false sense of eradication at all levels which can result in less priority of disease in policy and service level ii) revision of diagnostic criteria to address contagious form of leprosy iii) priority to be given to clustered and endemic area of leprosy iv) coordination to manage complications and disabilities iv) adequately train health care providers for detection and management of leprosy cases to avoid missing florid cases of leprosy which are major source of transmission in the community.

\section{CONCLUSION}

The prevalence of leprosy though below the elimination range is gradually reaching towards preelimination era. MB cases outnumbers PB cases in our scenario which are the major source of continued transmission in the community.

\section{CONFLICT OF INTEREST}

None declared.

\section{REFERENCES}

1. Lockwood D N.J. Leprosy. In: Griffiths C.E.M, Barker J, Bleiker T, Chalmers R,Creamer D editors .Rook's Textbook of Dermatology. West Sussex .UK: 9th ed. Wiley Blackwell; 2016: p. 28.1-28.18.

2. Guidelines for the diagnosis, treatment and prevention of Leprosy. New Delhi: World Health Organization, Regional office for South- East Asia; 2017. License: CC BY-NC-SA 3.0 IGO

3. Leprosy [Internet]; World health organization; 14th March 2019[Updated 2019 March 2019; cited 11th July 2019]: Available from https://www.who.int/news-room/ fact-sheets/detail/leprosy.

4. Government of Nepal, Ministry of Health and Population (NP). Annual report. Kathmandu (NP): Department of Health Services; 2016/17.380p. Report No: 23

5. Government of Nepal, Ministry of Health, Department of Health Services, Leprosy Control Division [Internet]. Nepal ;Leprosy control division, Teku, Kathmandu;2017[Cited May 2019]. Available from https://lcd.gov.np.

6. Paudel $U$, Parajuli S. Leprosy in Post-elimination Period: An experience in a single tertiary care centre in Kathmandu, Nepal. Nepal Journal of Dermatology, Venereology and Leprology.2019; 17(1):63-5.doi:http:// dx.doi.org/10.3126/njdvl.v.17i.123388.

7. Singhal A, Sonthalia S. Leprosy in Post- elimination era in India: Difficult journey ahead. Indian J Dermatol.2013; 58(6):443-6. Doi:10.4103/0019-5154.119952

8. Sengupta $U$. Elimination of Leprosy in India: An analysis. Indian J Dermatol Venereol Leprol [cited 2019 Jun 24];84;131-6. Available from :http://www.ijdvl.com/text. asp?2018/84/2/131/224889. 